\title{
Role of transient ischaemia and perioperative myocardial infarction in the genesis of new septal wall motion abnormalities after coronary bypass surgery
}

\author{
PAULO RIBEIRO, ^ PETROS NIHOYANNOPOULOS, SALAH FARAH, $\dagger$ D W MOSS,$\dagger$

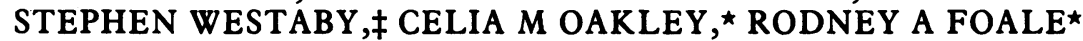

From the Departments of Medicine *(Clinical Cardiology), +Chemical Pathology, and the $\neq$ Cardiovascular Surgical Unit, Royal Postgraduate Medical School, Hammersmith Hospital, London

SUMMARY To evaluate the role of ischaemia in the genesis of new septal wall motion abnormalities after coronary artery bypass surgery 45 patients were studied by cross sectional echocardiography before and 8-10 days after operation. Regional left ventricular wall motion was classified as normal, hypokinetic, akinetic, or dyskinetic. Septal wall motion abnormalities were correlated with electrocardiographic $Q$ wave changes and serial serum $M B$ creatine kinase measured before and 4, 7, 21, 48 , and 72 hours after operation. Of the 14 patients who developed new septal wall motion abnormalities after operation two developed septal akinesis (both had perioperative infarction) and one new dyskinesis in the previously akinetic septal segment. Of the 11 patients with new septal hypokinesis, eight had normal serial creatine kinase MB values, two had raised values peaking four and seven hours after operation, with a return to normal values at 21 hours indicating transient ischaemia, and one had enzymatic criteria for perioperative infarction.

Most new echocardiographic septal wall motion abnormalities after coronary artery bypass grafting are not caused by transient ischaemia, perioperative infarction, or generalised cell necrosis.

A high incidence of new echocardiographic septal wall motion abnormalities has been detected after valvar heart surgery and coronary bypass surgery. ${ }^{1-3}$ The mechanisms underlying such new septal wall motion abnormalities are, however, controversial. ${ }^{4}$ Some workers stress the role of pericardiotomy with secondary loss of pericardial restraint in the origin of these abnormalities, ${ }^{4}$ while others favour perioperative ischaemia. ${ }^{2}$

The purpose of this study was to define the importance of transient myocardial ischaemia and perioperative myocardial infarction in the causation of new echocardiographic septal abnormalities after coronary artery bypass surgery.

\section{Patients and methods}

Sixty three consecutive patients admitted for coronary artery bypass graft surgery were studied with cross

Requests for reprints to Dr Celia M Oakley, Department of Clinical Cardiology, Hammersmith Hospital, Du Cane Road, London $W 12$ OHS.

Accepted for publication 2 May 1985 sectional echocardiography. Patients with unstable angina, left ventricular aneurysm, and additional non-coronary heart disease were excluded. Forty five (71\%) patients (42 men, three women; age range 38-65 (mean (SD) 51 (7) years) had technically satisfactory cross sectional echocardiograms, defined by the visualisation of septal left ventricular wall segments in at least three left ventricular short axis and one apical two chamber views. Thus 18 patients were excluded because of technically inadequate preoperative echocardiographic studies.

Patients in the study group had exertional angina and severe two and three vessel coronary disease. Of these, 24 had a previous history compatible with myocardial infarction, and 27 had regional wall abnormalities on left ventricular angiography (right anterior oblique single plane). None had symptoms or physical signs of right or left heart failure.

Each patient admitted to the study underwent $(a)$ routine 12 lead electrocardiography 24 hours before cardiac surgery and 8-10 days postoperatively, (b) cross sectional echocardiography 24 hours before and 8-10 days postoperatively, and (c) cardiac enzyme estimation, specifically of creatine kinase $\mathrm{MB}$, before 
operation (within 12 hours) and 4, 7, 48, and 72 hours after the end of cardiopulmonary bypass.

\section{CARDIAC SURGERY}

The surgical technique consisted of a median sternotomy and institution of cardiopulmonary bypass with bubble oxygenator, hypothermia $\left(27-30^{\circ}\right)$, and haemodilution (packed cell volume 20-25\%). Pump flow was maintained at $2.0 \mathrm{1} / \mathrm{m}^{2}$. Cold potassium cardioplegia was used for myocardial preservation. Reversed segments of saphenous veins were anastomosed to coronary arteries as appropriate. Proximal anastomoses were placed on the aortic wall under partial aortic clamping and during rewarming of the patient. Each patient received between two and six grafts (mean 3.4) and 13 patients underwent grafting and endarterectomy. Mean aortic cross clamping time ranged from 25 to 85 (mean 46) minutes and bypass time ranged from 59 to 125 (mean 84 ) minutes.

\section{CROSS SECTIONAL ECHOCARDIOGRAPHY}

All studies were performed using a mechanical sector scanner (ATL Mark 1, Squibb Medical Systems) with a $2.25 \mathrm{MHz}$ transducer. Each study was performed from standard parasternal, apical, and subcostal views and the patient was positioned to obtain the optimum images from each window. Images were recorded on a videotape for subsequent review and analysis. Each study was analysed by two independent observers. Where disagreement occurred a consensus was reached. Each study included at least three adequate short axis views in which more than $75 \%$ of the entire endocardial and epicardial outline but including the septum was visible throughout systole and diastole.

Segmental wall motion analysis was performed by dividing the left ventricle into five segment according to the classification of Kisslo et al. ${ }^{5}$ In this analysis, anterolateral, posterior, inferior, apical, and septal segments are identified from the three different transducer positions used. Anterolateral, posterior inferior, and septal segments are analysed from the 3-5 short axis views of the left ventricle recorded at the level of at least three of the following: (a) mitral valve leaflet; $(b)$ papillary muscle tip; $(c)$ papillary muscle body; $(d)$ papillary muscle base; and $(e)$ left ventricular apex. The apical segment is also assessed from the apical two chamber view. Regional left ventricular wall motion was graded for the septum by a modification of the terminology of Herman and Gorlin: 3, normal; 2 , hypokinetic; 1 , akinetic; and 0 , dyskinetic. ${ }^{6}$ As with qualitative angiographic analysis, wall motion in the septal segment was judged relative to the motion of other segments.

\section{CARDIAC ENZYME ESTIMATION}

Total creatine kinase activity was measured at $37^{\circ} \mathrm{C}$ by the Scandinavian recommended method with $N$-acetyl cysteine activation. ${ }^{7}$ All the results of creatine kinase and creatine kinase $\mathrm{MB}$ assays were tabulated according to the time of collection and the mean and standard deviations were calculated.

\section{DEFINITIONS}

ECG evidence of myocardial infarction-Q waves broader than $0.04 \mathrm{~s}$ in precordial or inferior leads were considered to be abnormal. ${ }^{8}$

Abnormal enzyme release-Creatine kinase MB release, indicating perioperative myocardial infarction, was defined as a peak activity in the serum of $>50 \mathrm{IU} / 1$ within 21 hours of operation. ${ }^{9}$ The time of maximal creatine kinase $M B$ activity was expressed in hours after the end of cardiopulmonary bypass. Transient reversible myocardial ischaemia was defined as a serum peak $\geqslant 40 \mathrm{IU} / 1$ 4-7 hours after

Table Results in 14 patients with new septal wall motion abnomalities after coronary artery bypass surgery (CABG)

\begin{tabular}{|c|c|c|c|c|c|c|c|c|c|}
\hline \multirow{2}{*}{$\begin{array}{l}\text { Case } \\
\text { No }\end{array}$} & \multicolumn{2}{|c|}{$\begin{array}{l}\text { Echocardiography } \\
\text { Septal wall motion }\end{array}$} & \multirow{2}{*}{$\begin{array}{l}\text { Pericardial } \\
\text { effusion }\end{array}$} & \multirow{2}{*}{$\begin{array}{l}E C G \\
\text { changes } \\
\text { after } \\
C A B G\end{array}$} & \multicolumn{4}{|c|}{$\begin{array}{l}\text { Creatine kinase } M B \text { activity }(I U / l) \\
\text { Before After }\left(\text { hova }^{\star}\right)\end{array}$} & \multirow{2}{*}{$\begin{array}{l}\text { Findings after } \\
C A B G\end{array}$} \\
\hline & Before & After & & & & 4 & 7 & 21 & \\
\hline $\begin{array}{r}1 \\
2 \\
3 \\
4 \\
5 \\
6 \\
7 \\
8 \\
9 \\
10 \\
11 \\
12 \\
13 \\
14\end{array}$ & $\begin{array}{l}\text { Normal } \\
\text { Normal } \\
\text { Normal } \\
\text { Normal } \\
\text { Normal } \\
\text { Normal } \\
\text { Normal } \\
\text { Normal } \\
\text { Normal } \\
\text { Normal } \\
\text { Normal } \\
\text { Normal } \\
\text { Akinetic } \\
\text { Normal }\end{array}$ & $\begin{array}{l}\text { Hypokinetic } \\
\text { Hypokinetic } \\
\text { Hypokinetic } \\
\text { Hypokinetic } \\
\text { Hypokinetic } \\
\text { Hypokinetic } \\
\text { Hypokinetic } \\
\text { Hypokinetic } \\
\text { Hypokinetic } \\
\text { Akinetic } \\
\text { Hypokinetic } \\
\text { Hypokinetic } \\
\text { Dyskinetic } \\
\text { Akinetic }\end{array}$ & $\begin{array}{l}- \\
+ \\
+ \\
+ \\
+ \\
+ \\
+ \\
+ \\
- \\
- \\
+ \\
+ \\
+ \\
-\end{array}$ & $\begin{array}{l}\text { ST-T } \\
\text { ST-T } \\
\text { ST-T } \\
\text { ST-T } \\
\text { ST-T } \\
\text { ST-T } \\
\text { ST-T } \\
\text { QS (V1-V4) }\end{array}$ & $\begin{array}{r}6 \\
2 \\
6 \\
8 \\
10 \\
2 \\
4 \\
12 \\
4 \\
4 \\
8 \\
4 \\
4 \\
10\end{array}$ & $\begin{array}{r}22 \\
0 \\
48 \\
14 \\
10 \\
6 \\
8 \\
86 \\
32 \\
14 \\
10 \\
20 \\
28 \\
14\end{array}$ & $\begin{array}{r}5 \\
13 \\
30 \\
8 \\
2 \\
2 \\
26 \\
86 \\
30 \\
26 \\
2 \\
28 \\
16 \\
2\end{array}$ & $\begin{array}{r}6 \\
4 \\
20 \\
2 \\
4 \\
4 \\
6 \\
76 \\
32 \\
24 \\
66 \\
4 \\
4 \\
4 \\
20 \\
124\end{array}$ & $\begin{array}{l}\text { Normal wall motion } \\
\text { Normal wall motion } \\
\text { Transient ischaemia } \\
\text { Normal wall motion } \\
\text { Normal wall motion } \\
\text { Normal wall motion } \\
\text { Myocardial infarction } \\
\text { Transient ischaemia } \\
\text { Normal wall motion } \\
\text { Myocardial infarction } \\
\text { Normal wall motion } \\
\text { Normal wall motion } \\
\text {.Normal wall motion } \\
\text { Myocardial infarction }\end{array}$ \\
\hline
\end{tabular}

*After the end of extracorporeal circulation.

-, absent; + , present 
operation with normal activity at 21 hours. 9

New postoperative septal motion abnomality was defined as a change in septal segment score of $\geqslant 1$ in the postoperative echocardiographic short axis view showing the maximum change in wall motion score.
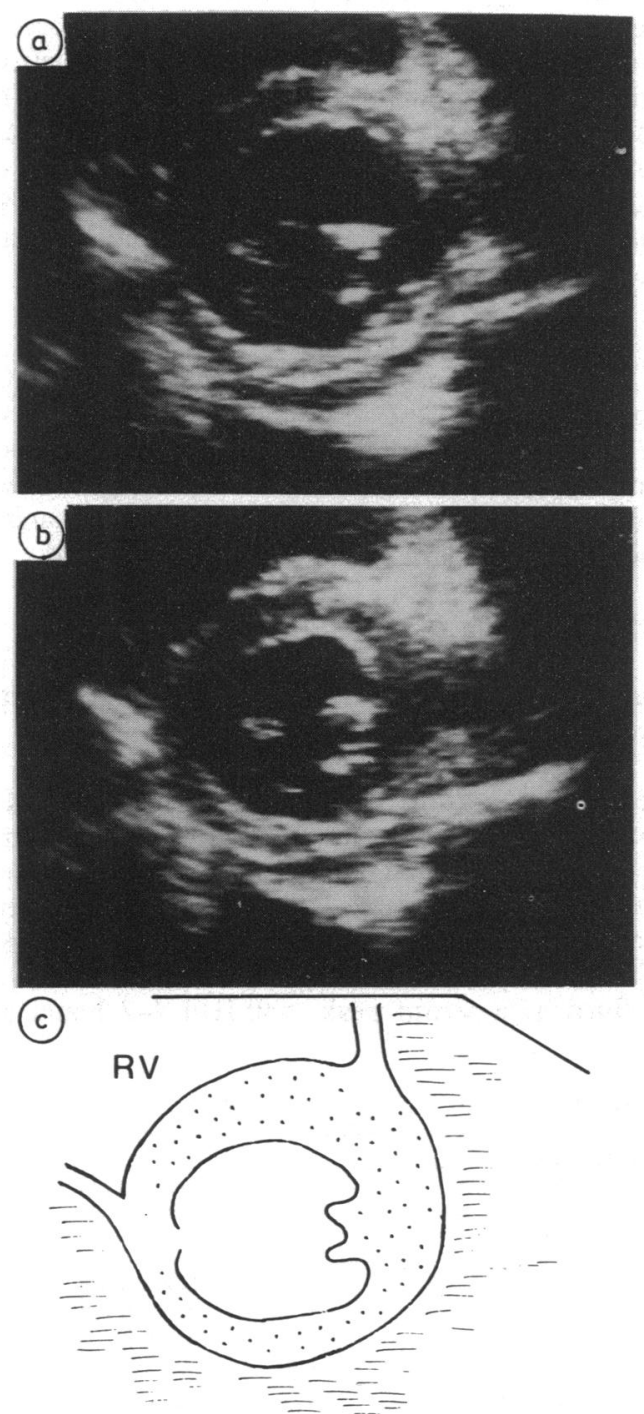

Figure Cross sectional echocardiographic short axis view of the left ventricle at the level of the papillary muscle tip. (a) Diastolic and (b) systolic stop frames show the echocardiographic suudy quality required to detect the septal endocardial signal so that (a) endocardial motion and (b) wall thickening can be described. This figure represents the average study quality in a patient who was classified as having normal septal wall motion preoperatively.
STATISTICAL ANALYSIS

Means and standard deviations were calculated in the usual way. Paired $t$ tests were used to test the difference between the means.

\section{Results}

\section{ECHOCARDIOGRAPHY}

Of the $\mathbf{4 5}$ patients with technically adequate preoperative echocardiograms 34 had septal segments that showed normal regional wall motion. Figure 1 shows a typical normal study. Eleven patients had septal segments that showed abnormal wall motion. Of these, five had hypokinetic segments, four akinetic, and two dyskinetic. The preoperative regional wall motion index was $2.58(0.84)$ (mean (SD)). After operation, the index for the 45 patients decreased to $2.14(0.83)(p<0.001)$. Thirty $(67 \%)$ septal segments were unchanged in the postoperative study, 14 had deteriorated, and one improved.

\section{Segments deteriorated (Table)}

Akinesis-Of the 14 septal segments that deteriorated, two showed new akinesis after normal preoperative motion. Both patients had perioperative myocardial infarction based on creatine kinase MB criteria, but only one patient had new electrocardiographic $\mathbf{Q}$ waves.

Hypokinesis-Eleven segments became hypokinetic postoperatively after preoperative motion had been normal. Of these, eight had normal serial creatine kinase $M B$ values after operation and two had an abnormal rise in enzyme activity without electrocardiographic ST-T wave changes. Creatine kinase MB values peaked between four and seven hours in these patients but were within normal values at 21 hours, indicating transient ischaemia. ${ }^{10}$ In one of the 11 patients activity peaked at 21 hours, and this patient was considered to have perioperative myocardial infarction. ${ }^{9}$

Dyskinesis-One segment that had been akinetic before operation became dyskinetic. This patient had no electrocardiographic or enzymatic change.

A total of 11 patients therefore had new septal abnormalities but no enzymatic or electrocardiographic evidence of perioperative myocardial infarction; nine had an associated mild or moderate pericardial effusion.

\section{Segments improved}

Only one preoperatively abnormal septal segment improved, from dyskinetic to akinetic. This was not associated with pericardial effusion or an abnormal rise in creatine kinase $M B$ activity. Of the 10 other septal segments that were abnormal preoperatively, none showed any change in the postoperative study. 


\section{Discussion}

We detected a high incidence (24\%) of new septal wall motion abnormalities after coronary bypass surgery in our patients. Although ischaemic damage may have been responsible for septal hypokinesia in two patients and perioperative infarction may have occurred in three patients, perioperative infarction and transient ischaemia were not the cause of most of these new septal abnormalities. Experimental studies have shown that brief periods of ischaemia can depress myocardial function. This injury is reversible with time, although the structural, metabolic, and functional properties of the myocardium may remain severely disturbed for days before recovery. ${ }^{1011}$ This phenomenon may explain the late normalisation of surgically induced septal wall motion abnormalities in one patient reported by Rubenson et al studied some weeks after operation. ${ }^{12}$ Our results, however, support a recent radionuclide study of patients with abnormal septal wall motion after coronary bypass surgery who had normal thallium-201 perfusion scans of this region. ${ }^{13}$ Our findings of normal enzyme patterns in most patients with new abnormal septal motion support the notion that factors other than ischaemia or infarction are operating.

We found an association between septal hypokineasia and pericardial effusion. Several explanations for this phenomenon are possible. Septal hypokinesia has been reported in patients with constrictive pericarditis and with major pericardial effusion. ${ }^{14} 15$ In some of our patients therefore the presence of a moderate sized pericardial effusion may have been responsible for the septal abnormality. We have also noted abnormal echoes that appear to represent organised clot in part of the anterior right ventricular wall in most patients after coronary artery bypass surgery. These clots may therefore contribute to the abnormal septal wall motion without there necessarily being an additional large pericardial effusion. Recent intraoperative echocardiographic studies suggest that the pericardiotomy itself is responsible for septal wall motion disturbances secondary to excessive anterior cardiac mobility. ${ }^{4}$ This finding is supported by reports that septal hypokinesia is seen in patients with congenital absence of the pericardium. ${ }^{16}$ At our institution the pericardium is always left open but does not remain so since subsequent healing and a variable amount of epicardial and mediastinal adhesion inevitably occurs. This is consistent with the observation that most septal abnormalities tend to return to normal with time, ${ }^{13}$ and indeed Righetti et al speculated that postoperative adhesions could lead to late normalisation of septal wall motion. ${ }^{2}$

Echocardiographic septal hypokinesia has also been reported after valve surgery. ${ }^{1}$ Ventriculotomy cannot be implicated as a possible mechanism since septal hypokinesia is not seen in patients undergoing mitral valvotomy. ${ }^{1}$ Furthermore, septal abnormalities have been found in patients undergoing cardiac surgery without a ventriculotomy. ${ }^{2}$ Although all our patients had septal hypokinesia or akinesia, none had associated right ventricular volume overload or electromechanical, ${ }^{17}$ structural, ${ }^{18}$ or other pathophysiological ${ }^{19}$ conditions that are known to be associated with abnormal septal wall motion. ${ }^{7}$

In two patients perioperative myocardial infarction resulted in new septal akinesia with an abnormal rise (>50 IU/l) in serum creatine kinase MB activity 21 hours after the end of cardiopulmonary bypass indicating irreversible myocardial damage. ${ }^{9} \mathrm{~A}$ few of our patients with new septal hypokinesis showed an abnormal rise in creatine kinase MB activity peaking between four and seven hours but with normalisation at 21 hours indicating transient ischaemia. Creatine kinase MB is a very sensitive chemical indicator of myocardial damage, and abnormal rises in its activity are detected after episodes of stable and unstable angina. ${ }^{20}$ The qualitative detection on single quantitation estimates of the enzyme by itself is, however, not specific for the diagnosis of perioperative infarction. ${ }^{21} 22$ Histochemical and untrastuctural studies have shown that the cellular changes after cardiopulmonary bypass grafting closely resemble changes seen after reperfusion of ischaemic regions. ${ }^{23}$ This ischaemic insult may result in changes in myocardial cell permeability, ${ }^{24}$ which in turn could lead to a "stunned" septal segment. ${ }^{10}$ It is reasonable to suppose therefore that changes in membrane permeability promote cellular depletion of creatine kinase MB. 2022

In conclusion this study has shown that transient myocardial ischaemia or generalised cell necrosis are not responsible for the majority of new septal wall motion abnormalities after coronary bypass graft surgery. New echocardiographic septal wall akinesia may be a marker of perioperative infarction but appears to be most frequently associated with intrapericardial collections.

\section{References}

1 Burggraf GW, Craige E. Echocardiographic studies of left ventricular wall motion and dimensions after valvular heart surgery. Am $\mathcal{F}$ Cardiol 1975; 35: 473-80.

2 Righetti A, Crawford MH, O'Rourke RA, Schelbert H, Daily PO, Ross J, Jr. Interventricular septal motion and left ventricular function after coronary bypass surgery. Evaluation with echocardiography and radionuclide angiography. Am $\mathcal{F}$ Cardiol 1977; 39: 372-7.

3 Matsumoto M, Oka Y, Strom J, et al. Application of transeosophageal echocardiography to continuous intraoperative monitoring of left ventricular performance. Am f Cardiol 1980; 46: 95-105. 
4 Waggoner AD, Shah AA, Schuessier JS, et al. Effect of cardiac surgery on ventricular septal motion: assessment by intraoperative echocardiography and cross-sectional two-dimensional echocardiography. Am Heart f 1982; 104: 1271-8.

5 Kisslo JA, Robertson D, Gilbert BW, Von Ramm O, Behar VS. A comparison of real-time, two-dimensional echocardiography and cineangiography in detecting left ventricular asynergy. Circulation 1977; 55: 134-41.

6 Herman MV, Gorlin R. Implications of left ventricular asynergy. Am F Cardiol 1969; 23: 538-47.

7 Scandinavian Society for Clinical Chemistry and Clinical Physiology Committee on enzymes. Recommended method for the determination of creatine kinase in blood modified by the inclusion of EDTA. Scand $\mathcal{F}$ Clin Lab Invest 1979; 39: 1-5.

8 New York Heart Association Criteria Committee. Nomenclature and criteria for diagnosis of diseases of the heart and great vessels. 8th ed. Boston: Little, Brown, 1979.

9 Fara SY, Moss DW, Ribeiro P, et al. Interpretation of changes in the activity of creatinine kinase MB isoenzyme in serum after coronary artery bypass grafting. Clin Chim Acta 1984; 141: 219-25.

10 Braunwald E, Kloner RA. The stunned myocardium: prolonged post-ischemic ventricular dysfunction. Circulation 1982; 66: 1146-9.

11 Ninomiya K, Hashida J, Geft I, et al. Brief repeat periods of ischemia have a cumulative effect and may cause myocardial necrosis [Abstract]. Am f Cardiol 1981; 47: 445.

12 Rubenson DS, Tucker CR, London E, Miller DC, Stinson EB, Popp RL. Two-dimensional echocardiographic analysis of segmental left ventricular wall motion before and after coronary artery bypass surgery. Circulation 1982; 66: 1025-33.

13 Murphy JH, Okada RD, Boucher CA, Strauss HW, Pohost GM, Daggett WA. Relationship between septal perfusion and abnormal septal motion after coronary artery bypass surgery [Abstract]. Am $\mathcal{F}$ Cardiol 1982; 49: 919.
14 Vignola PA, Pohost GM, Curfman GD, Myers GS. Correlation of echocardiographic and clinical findings in patients with pericardial effusion. Am F Cardiol 1976; 37: 701-7.

15 Candell-Riera J, García del Castillo H, PermanyerMiralda G, Soler-Soler J. Echocardiographic features of the interventricular septum in chronic constrictive pericarditis. Circulation 1978; 57: 1154-8.

16 Payvandi MN, Kerber RE. Echocardiography in congenital and acquired absence of the pericardium. Circulation 1976; 53: 86-8.

17 Dillon JC, Chang S, Feigenbaum H. Echocardiographic manifestations of left bundle branch block. Circulation 1974; 49: 876-80.

18 Jacobs JJ, Feigenbaum H, Corya BC, Phillips JF. Detection of left ventricular asynergy by echocardiography. Circulation 1973; 48: 263-71.

19 Hagan AD, Francis GS, Sahn DJ, Karliner JS, Friedman WF, O'Rourke RA. Ultrasound evaluation of systolic anterior septal motion in patients with and without right ventricular volume overload. Circulation 1973; 50: 248-54.

20 Lott JA, Stang JM. Serum enzymes and isoenzymes in the diagnosis and differential diagnosis of myocardial ischemia and necrosis. Clin Chem 1980; 26: 1241-50.

21 Kraft J, Aastrup H, Schrøder P. Diagnostic value for acute myocardial infarction of creatinine kinase and lactate dehydrogenase isoenzymes compared with total enzymes. Acta Med Scand 1978; 203: 167-74.

22 Ruff WL, Worrell $\mathrm{R}, \mathrm{Ng} \mathrm{K}$. Diagnostic value of creatinine phosphokinase (CPK) isoenzymes in the absence of elevated total CPK. F Natl Med Assoc 1979; 71: 383-6.

23 Reichenbach DD, Benditt EP. Myofibrillar degeneration: a response of the myocardial cell to injury. Arch Pathol 1968; 85: 189-99.

24 Delva E, Maille JG, Solymoss BC, Chabot M, Grondin CM, Bourassa MG. Evaluation of myocardial damage during coronary artery grafting with serial determinations of serum CPK MB isoenzyme. F Thorac Cardiovasc Surg 1978; 75: 467-75. 